Research Article

\title{
Association of Breastfeeding Counselling with Infant Breastfeeding Practices among Lactating Mothers of Rural Area of Haryana: A Cross- Sectional Study
}

Privanka Choudhary', Dhriti Bapna ${ }^{2}$, Anand Jain ${ }^{3}$, RB Jain ${ }^{4}$, Amit Kumar Mital $^{5}$, Gerish Atri ${ }^{6}$, Rajat Gupta ${ }^{7}$

${ }^{1,2}$ Senior Resident, ${ }^{4}$ Senior Professor, ${ }^{6,7}$ Junior Resident, Department of Community Medicine, Pt. B.D. Sharma PGIMS, Rohtak, India.

${ }^{3}$ Senior Resident, Department of Medicine, Pt. B.D Sharma PGIMS, Rohtak and Baba Saheb Ambedkar Medical College, New Delhi, India.

${ }^{5}$ Assistant Professor, Department of Pediatrics, World College of Medical Sciences and Research and Hospital, Jhajjar, India. DOI: https://doi.org/10.24321/2454.325X.202014

I $\quad \begin{array}{lll}\mathbf{N} & \mathbf{F} & \mathbf{O}\end{array}$

Corresponding Author:

Amit Kumar Mital, Department of Pediatrics, World College of Medical Sciences and Research and Hospital, Jhajjar, India.

E-mail Id:

mittal1.amit@gmail.com

Orcid Id:

https://orcid.org/0000-0002-5315-3663

How to cite this article:

Choudhary P, Bapna D, Jain A, Jain RB, Mital AM, Atri $G$ et al. Association of Breastfeeding Counselling with Infant Breastfeeding Practices among Lactating Mothers of Rural Area of Haryana: A Cross-Sectional Study. Int J Preven Curat Comm Med 2020; 6(4): 1-8.

Date of Submission: 2021-02-15

Date of Acceptance: 2021-03-25
$\begin{array}{llllllll}\mathbf{A} & \mathbf{B} & \mathbf{S} & \mathbf{T} & \mathbf{R} & \mathbf{A} & \mathbf{C} & \mathbf{T}\end{array}$

Background: Breastfeeding is fundamental to the health and development of children and important for the health of their mothers. Correct information, timely initiation and duration of Breastfeeding, family support and weaning practices are important aspects. Health care professionals play a critical role in influencing decisions about feeding practices among mothers and families.

Methodology: A community based cross-sectional study was conducted in rural area of Haryana over a period of 12 months commencing from March 2019. Multistage sampling technique was used to enroll 200 infants aged 6-11 completed months and their mothers who were willing to participate in the study. Appropriate statistical tests were used in form of percentages, chi square and logistic regression.

Result: Mothers receiving 3, 4 and $>4$ antenatal check-ups were 1.6, 2.7 and 2.1 times more likely to get ANC counselling in comparison to women with single antenatal check-up done. Women's literacy played a significant role in receiving antenatal counselling $(p=0.035)$. Infant feeding practices like giving colostrum, starting feeding within 1 hour of delivery, burping after feed, exclusive breastfeeding for 1 week, 1 month, 3 months and 6 months etc were followed more among educated mothers and those given antenatal breastfeeding counselling but the association was statistically non-significant.

Conclusion: This study concludes that antenatal breastfeeding counseling is very useful for exclusive Breastfeeding and for improving infant breastfeeding practices.

Keywords: Antenatal Breastfeeding Counselling, Exclusive Breastfeeding, Infant Breastfeeding Practices, Rural Area 


\section{Introduction}

Breastfeeding is fundamental to the health and development of children and important for the health of their mothers. The universal breastfeeding practices is a life line for the newborns as it provides all the energy and nutrients needed during the initial months of life. ${ }^{1}$ According to WHO, colostrum is the perfect food for the newborns and feeding should be initiated as early as possible ideally within the first hour after birth. Exclusive breastfeeding is recommended up to 6 months of age, with continued breastfeeding along with appropriate complementary foods up to two years of age.

There are several well-established benefits of breastfeeding on health and wellbeing of both the mother and baby. ${ }^{2}$ It is said to be highly effective intervention against the major three causes for the child mortality (neonatal sepsis, diarrhea and pneumonia). A cross-national analysis of 57 low and middle income countries revealed that, 10 percentage-points increase in exclusive breastfeeding was associated with a reduction of 5 child deaths per 1,000 live births. ${ }^{3}$ Correct information, timely initiation and duration of Breastfeeding, family support and weaning practices are important aspects, which have to be learnt, practiced and it needs a lot of determination, patience and effort on the part of the mother.

Health care professionals play a critical role in influencing decisions about feeding practices among mothers and families. ${ }^{4}$ Exclusive Breastfeeding upto 6 months can prevent upto $13 \%$ of the estimated under-five deaths. Breastfeeding also provides constant positive interactions between mother and child which can contribute to emotional and psychological development of infants. It has been found to have direct positive impact on brain development. ${ }^{5}$ Breastfeeding has a protective effect against childhood obesity and lowers the risk of several chronic conditions including asthma, diabetes and heart disease, in adult life and thus contributes to long-term benefits. In low income countries breastfeeding represents the only way of giving a child a fair chance of survival and good health.

However, with the artificial feeding substitutes readily available and the traditional universal Breastfeeding on a decline, in terms of incidence as well as duration, it is now a public health concern. The rates of early initiation, exclusive breastfeeding and timely complementary feeds are far from desirable. A number of factors including ignorance, undesirable socio-cultural beliefs and misconceptions, counselling by health workers and practices among peers or other community members influence the breastfeeding practices of the mothers. Considering the above aspects this study was conducted to assess the Breastfeeding practices and the association of mother's education and antenatal counselling on Breastfeeding duration practices among lactating mothers having infants.

\section{Material and Methods}

A community based cross-sectional study was conducted in area of Community Health Centre $(\mathrm{CHC})$ Dighal (District Jhajjar, Haryana), which is the rural field practice area attached to Department of Community Medicine, Pt. B. D. Sharma PGIMS, Rohtak. The study was conducted over a period of 12 months commencing from March 2019. The study population comprised of infants aged 6-11 completed months and their mothers who were willing to participate in the study. Also infants who were apparently healthy for the last one month before enrolment for the study, with or without some minor childhood ailments were included in the study.

\section{Exclusion Criteria}

- Infants having history of prolonged or severe illness requiring hospitalization

- Infants having congenital anomalies causing adverse effect on their growth

- Infants born to mothers with history of chronic disease that might affect child's growth (Diabetes, Tuberculosis, Mental illness)

- Separation from mother (death, divorce, adoption)

\section{Sample Size}

Taking the prevalence of exclusive Breastfeeding in Haryana as $50.4 \%$, which has been reported by NFHS 4 (2015-16 $)^{6}$ and further taking the allowable error to be $15 \%$ of the prevalence, the sample size came out to be 178 . So for the purpose of present study 200 subjects were enrolled.

\section{Sampling Techniques}

Multistage sampling technique was used for enrolling the required 200 study subjects. All 5 PHCs under $\mathrm{CHC}$ Dighal and all 20 sub-centres of these 5 PHCs were selected for the study. Two anganwadi centres (AWC) were randomly selected by lottery method from each of these sub-centre areas and thus total 40 AWCs were included in the study. List of infants having six months to one year of age was prepared from each of these anganwadi and out of this list five infants were selected by simple random sampling technique.

Home visits were made by the investigator himself accompanied by MPHW (F)/ ASHA/ AWW and an informed written consent, was obtained from the mothers of infants for participating in the study after informing them about the purpose of study.

The data were collected using a pre-designed, pre-tested semi-structured schedule which was piloted on 20 subjects for the feasibility of administration of questions and modifications were made, before the commencement of study. For defining socio-economic status, modified B.G. Prasad classification $(2019)^{7}$ was used. 


\section{Statistical Analysis}

The data were collected and entered in the MS EXCEL spread sheet and then the data were subjected to appropriate statistical tests using SPSS 20 (Statistical package for social sciences) software. Descriptive statistics in terms of percentages and inferential statistics as chi square test was used for qualitative data. Binominal logistic regression was applied for variables whose $p$ value was $<0.05$.

\section{Ethics}

Ethics approval was obtained from the ethics committee of Pt. B.D Sharma PGIMS Rohtak and written informed consent was obtained from the parent of the patients.

\section{Result}

Out of 200 infants enrolled in study, 108 (54\%) were male and 92 (46\%) were females. There was almost uniform distribution of infants in age groups of 6-11 completed months. The mean age of infants was 9 months \pm 1.87 .194$ $(97 \%)$ mothers belonged to age group of $18-35$ years and 186 (93\%) mothers were literate. Maximum mothers (94\%) were home maker. 162 (81\%) had normal vaginal delivery and $38(19 \%)$ had caesarean section. 110 mothers had more than one child out of which $41(37.4 \%)$ maintained a gap of $2-3$ years and more than 3 years each while 28 (25.4\%) delivered within 2 years of previous child.

Mothers were grouped in two categories on the basis of those who received breastfeeding counselling during their antenatal period $[n=159(79.5 \%)]$ and those who did not receive breastfeeding counselling during their antenatal period [ $n=41(20.5 \%)$ ]. Table 1 shows that Breastfeeding counselling had a significant association with duration of exclusive Breastfeeding. The women who received breastfeeding counselling had 4.12 times, 4.34 times, 3.82 times and 2.04 times more chances of exclusively breastfeeding their baby till 1 week, 1 month, 3 months and 6 months respectively than those who had not received any counselling.

Table 2 shows association of Breastfeeding counselling with sociodemographic variables and antenatal details. It was observed that mother's literacy level and number of antenatal check-ups received had a significant association with receiving of antenatal breastfeeding counselling. Mothers receiving 3, 4 and $>4$ antenatal check-ups were 1.6, 2.7 and 2.1 times more likely to get ANC counselling in comparison to women with 1 antenatal check-ups done.

It was found that factors related to infant feeding like first food offered, colostrum given, burping done after feed, night feeding etc. had no significant association with breastfeeding counselling which is shown in Table 3.

Table 4 shows the association of mother's education with factors related to infant feeding practices. Only factor which showed significant association with mother's education was burping done after feeding ( $p=0.009)$.

Table I.Association of Breastfeeding counselling with duration of exclusive Breastfeeding

\begin{tabular}{|c|c|c|c|c|c|c|}
\hline $\begin{array}{l}\text { Type of feed } \\
\text { given }\end{array}$ & $\begin{array}{c}\text { Breastfeeding } \\
\text { counselling given } \\
\text { during ANC, } n=159 \\
(79.5 \%)\end{array}$ & $\begin{array}{c}\text { Breastfeeding } \\
\text { counselling not } \\
\text { given during ANC, } \\
\mathrm{n}=41(20.5 \%)\end{array}$ & $\begin{array}{l}\text { Total, } \\
n=200\end{array}$ & $p$ value & $\begin{array}{c}\text { Unadjusted } \\
\text { prevalence ratio } \\
(95 \% \mathrm{Cl})\end{array}$ & $p$ value \\
\hline \multicolumn{7}{|c|}{ Type of feed given at 1 week } \\
\hline Only Breast milk & $146(91.8 \%)$ & $30(73.2 \%)$ & $176(88 \%)$ & 0.001 & $4.12(1.68-10.07)$ & \multirow[b]{2}{*}{0.002} \\
\hline $\begin{array}{c}\text { Mix feed or other } \\
\text { feed given }\end{array}$ & $13(8.2 \%)$ & $11(26.8 \%)$ & $24(12 \%)$ & & Reference & \\
\hline \multicolumn{7}{|c|}{ Type of feed given at 1 month } \\
\hline Only Breast milk & $148(93.1 \%)$ & $31(75.6 \%)$ & $179(89.5 \%)$ & 0.001 & $4.34(1.69-11.11)$ & \multirow[b]{2}{*}{0.002} \\
\hline $\begin{array}{l}\text { Mix feed or other } \\
\text { feed given }\end{array}$ & $11(6.9 \%)$ & $10(24.4 \%)$ & $21(10.5 \%)$ & & Reference & \\
\hline \multicolumn{7}{|c|}{ Type of feed given at 3 month } \\
\hline Only Breast milk & $140(88.1 \%)$ & 27 (65.9\%) & $167(83.5 \%)$ & 0.001 & $3.82(1.71-8.54)$ & \multirow[b]{2}{*}{0.001} \\
\hline $\begin{array}{l}\text { Mix feed or other } \\
\text { feed given }\end{array}$ & 19 (11.9\%) & $14(34.1 \%)$ & $33(16.5 \%)$ & & Reference & \\
\hline \multicolumn{7}{|c|}{ Type of feed given at 6 month } \\
\hline Only Breast milk & $115(72.3 \%)$ & $23(56.1 \%)$ & $138(69 \%)$ & 0.045 & $2.04(1.01-4.15)$ & \multirow[b]{2}{*}{0.048} \\
\hline $\begin{array}{c}\text { Mix feed or other } \\
\text { feed given }\end{array}$ & $44(27.7 \%)$ & $18(43.9 \%)$ & $62(31 \%)$ & & Reference & \\
\hline
\end{tabular}


Table 2.Association of breast feeding counselling with sociodemographic variables and antenatal details

\begin{tabular}{|c|c|c|c|c|}
\hline & $\begin{array}{l}\text { Breastfeeding counselling } \\
\text { given during ANC }\end{array}$ & $\begin{array}{l}\text { Breastfeeding counselling } \\
\text { not given during ANC }\end{array}$ & Total & $P$ value \\
\hline \multicolumn{5}{|l|}{ Age of mother } \\
\hline 18 yrs -35 yrs & $155(79.9 \%)$ & $39(20.1 \%)$ & $194(97 \%)$ & \multirow{2}{*}{0.430} \\
\hline$>35$ yrs & $4(66.7 \%)$ & $2(33.3 \%)$ & $6(3 \%)$ & \\
\hline \multicolumn{5}{|l|}{ Mother's education } \\
\hline Illiterate & $9(57.1 \%)$ & $6(42.9 \%)$ & $15(7 \%)$ & \multirow{2}{*}{0.052} \\
\hline Literate & $150(81.2 \%)$ & $35(18.8 \%)$ & $185(93 \%)$ & \\
\hline \multicolumn{5}{|c|}{$\begin{array}{c}\text { Mother's literacy level, } \mathrm{n}=185 \\
\text { (93\% literate) }\end{array}$} \\
\hline Primary & $11(78.6 \%)$ & $3(21.4 \%)$ & $14(7.5 \%)$ & \multirow{5}{*}{0.035} \\
\hline Middle & $15(62.5 \%)$ & $9(37.5 \%)$ & 24 (12.9\%) & \\
\hline Secondary & $31(77.5 \%)$ & $9(22.5 \%)$ & $40(21.5 \%)$ & \\
\hline Higher secondary & $49(92.5 \%)$ & $4(7.5 \%)$ & $53(28.5 \%)$ & \\
\hline Graduate & $45(81.8 \%)$ & $10(18.2 \%)$ & $55(29.6 \%)$ & \\
\hline \multicolumn{5}{|l|}{ Mother's occupation } \\
\hline Home maker & $149(79.3 \%)$ & $39(20.7 \%)$ & $188(94 \%)$ & \multirow{2}{*}{0.734} \\
\hline Working woman & $10(83.3 \%)$ & $2(16.7 \%)$ & $12(6 \%)$ & \\
\hline \multicolumn{5}{|l|}{ Socioeconomic status } \\
\hline Upper class & $9(64.3 \%)$ & $5(35.7 \%)$ & $14(7 \%)$ & \multirow{5}{*}{0.230} \\
\hline Upper middle class & 31 (83.8\%) & $6(16.2 \%)$ & 37 (18.5\%) & \\
\hline Middle class & 39 (88.6\%) & $5(11.4 \%)$ & $44(22 \%)$ & \\
\hline Lower middle class & $49(77.8 \%)$ & $14(22.2 \%)$ & $63(31.5 \%)$ & \\
\hline Lower class & $31(73.8 \%)$ & $11(26.2 \%)$ & $42(21 \%)$ & \\
\hline \multicolumn{5}{|l|}{ Type of family } \\
\hline Joint & $133(80.1 \%)$ & 33 (19.9\%) & $166(83 \%)$ & \multirow{2}{*}{0.631} \\
\hline Nuclear & $26(76.5 \%)$ & $8(23.5 \%)$ & $34(17 \%)$ & \\
\hline \multicolumn{5}{|c|}{ Total number of children } \\
\hline 1 & $66(77.6 \%)$ & $19(22.4 \%)$ & $85(42.5 \%)$ & \multirow{5}{*}{0.324} \\
\hline 2 & $74(80.4 \%)$ & $18(19.6 \%)$ & $92(46 \%)$ & \\
\hline 3 & $15(93.8 \%)$ & $1(6.2 \%)$ & $16(8 \%)$ & \\
\hline 4 & $2(66.7 \%)$ & $1(33.3 \%)$ & $3(1.5 \%)$ & \\
\hline 5 & $2(50 \%)$ & $2(50 \%)$ & $4(2 \%)$ & \\
\hline \multicolumn{5}{|c|}{ Number of ANC check ups } \\
\hline 0 & 0 & 4 & $4(2 \%)$ & \multirow{6}{*}{0.001} \\
\hline 1 & $3(1.5 \%)$ & 0 & $3(1.5)$ & \\
\hline 2 & $13(81.2 \%)$ & $3(18.8 \%)$ & $16(8)$ & \\
\hline 3 & $28(71.8 \%)$ & $11(28.2)$ & $39(19.5)$ & \\
\hline 4 & $39(76.5 \%)$ & $12(23.5)$ & $51(25.5)$ & \\
\hline$>4$ & $76(87.4 \%)$ & $11(12.6)$ & $87(43.5)$ & \\
\hline
\end{tabular}




\begin{tabular}{|c|c|c|c|l|}
\hline Birth weight & & & & \\
\hline LBW & $27(69.2 \%)$ & $12(30.8 \%)$ & $39(19.5 \%)$ & \multirow{2}{*}{0.077} \\
\hline Normal & $132(82 \%)$ & $29(18 \%)$ & $161(80.5 \%)$ & \\
\hline
\end{tabular}

Table 3.Association of breast feeding counselling with factors related to feeding of infant

\begin{tabular}{|c|c|c|c|c|}
\hline & $\begin{array}{c}\text { Breastfeeding counselling } \\
\text { given during ANC, } n=159 \\
(79.5 \%)\end{array}$ & $\begin{array}{c}\text { Breastfeeding counselling } \\
\text { not given during ANC, } \\
n=41(20.5 \%)\end{array}$ & $\begin{array}{l}\text { Total, } \\
\mathrm{n}=\mathbf{2 0 0}\end{array}$ & $\begin{array}{c}\mathbf{p} \\
\text { value }\end{array}$ \\
\hline \multicolumn{5}{|c|}{ First food given to infant } \\
\hline Breast milk only & $130(80.7 \%)$ & $31(19.3 \%)$ & $161(80.5 \%)$ & \multirow{2}{*}{0.375} \\
\hline Other feed & $29(74.4 \%)$ & $10(25.6 \%)$ & 39 (19.5\%) & \\
\hline \multicolumn{3}{|c|}{ Colostrum feeding } & & \\
\hline Given & 147 (79.5\%) & $38(20.5 \%)$ & 185 (92.5\%) & \multirow{2}{*}{0.96} \\
\hline Not given & $12(80 \%)$ & $3(20 \%)$ & $15(7.5 \%)$ & \\
\hline \multicolumn{5}{|c|}{$\begin{array}{l}\text { Breastfeed given within } 1 \\
\text { hour after birth }\end{array}$} \\
\hline Yes & $118(82.5 \%)$ & $25(17.5 \%)$ & $143(71.5 \%)$ & 0.094 \\
\hline No & $41(71.9 \%)$ & $16(28.1 \%)$ & $57(28.5 \%)$ & \\
\hline \multicolumn{5}{|c|}{ Motivation to feed till 2 years } \\
\hline Fully & $104(80.6 \%)$ & 25 (19.4\%) & $129(64.5 \%)$ & \multirow{3}{*}{0.467} \\
\hline Partial & $37(74 \%)$ & $13(26 \%)$ & $50(25 \%)$ & \\
\hline Not motivated & $18(85.7 \%)$ & $3(14.3 \%)$ & $21(10.5 \%)$ & \\
\hline \multicolumn{5}{|c|}{ Breastfeeding done at night } \\
\hline Yes & $141(79.7 \%)$ & $36(20.3 \%)$ & $177(95.7 \%)$ & \multirow{2}{*}{0.588} \\
\hline No & $7(87.5 \%)$ & $1(12.5 \%)$ & $8(4.3 \%)$ & \\
\hline \multicolumn{5}{|c|}{ Burping after breast feed } \\
\hline Yes & $136(81 \%)$ & $32(19 \%)$ & $168(90.8 \%)$ & \multirow{2}{*}{0.309} \\
\hline No & $12(70.6 \%)$ & $5(29.4 \%)$ & $17(9.2 \%)$ & \\
\hline \multicolumn{5}{|c|}{ Timing of Breastfeeding } \\
\hline Demand & $46(75.4 \%)$ & $15(24.6 \%)$ & $61(33 \%)$ & \multirow{2}{*}{0.167} \\
\hline Interval & 104 (83.9\%) & 20 (16.1\%) & $124(67 \%)$ & \\
\hline
\end{tabular}

Table 4.Association of mother's education with factors related to feeding of infant

\begin{tabular}{|c|c|c|c|c|}
\hline & $\begin{array}{c}\text { Mother illiterate } \\
\quad \mathrm{n}=15(7 \%)\end{array}$ & $\begin{array}{c}\text { Mothers literate } \\
\mathrm{n}=185 \text { (93\%) }\end{array}$ & Total $(n=200)$ & $\mathrm{p}$ value \\
\hline \multicolumn{5}{|c|}{ First food given to infant } \\
\hline Breast milk only & $13(8.1 \%)$ & 148 (91.9\%) & $161(80.5 \%)$ & \multirow{2}{*}{0.531} \\
\hline Other feed & $2(5.1 \%)$ & 37 (94.9\%) & 39 (19.5\%) & \\
\hline \multicolumn{5}{|l|}{ Colostrum feeding } \\
\hline Given & $14(93.3 \%)$ & $171(92.4 \%)$ & $185(92.5 \%)$ & \multirow{2}{*}{0.96} \\
\hline Not given & $1(6.7 \%)$ & $14(7.6 \%)$ & $15(7.5 \%)$ & \\
\hline \multicolumn{5}{|c|}{ Breastfeed given within 1 hour after birth } \\
\hline Yes & $10(66.7 \%)$ & $133(71.9 \%)$ & $143(71.5 \%)$ & \multirow{2}{*}{0.666} \\
\hline No & 5 (33.3\%) & 52 (28.1\%) & 57 (28.5\%) & \\
\hline
\end{tabular}




\begin{tabular}{|c|c|c|c|c|}
\hline Motivation to feed till 2 years & & & & \\
\hline Fully & $12(80 \%)$ & $117(63.2 \%)$ & $129(64.5 \%)$ & \multirow{3}{*}{0.424} \\
\hline Partial & $2(13.3 \%)$ & $48(25.9 \%)$ & $50(25 \%)$ & \\
\hline Not motivated & $1(6.7 \%)$ & $20(10.8 \%)$ & $21(10.5 \%)$ & \\
\hline \multicolumn{5}{|l|}{ Burping after breast feed } \\
\hline Yes & $10(71.4 \%)$ & $158(92.4 \%)$ & $168(90.8 \%)$ & \multirow{2}{*}{0.009} \\
\hline No & $4(28.6 \%)$ & $13(7.6 \%)$ & $17(9.2 \%)$ & \\
\hline \multicolumn{5}{|l|}{ Type of feed given at 1 week } \\
\hline Only Breast milk & $11(73.3 \%)$ & $165(89.2 \%)$ & $176(88 \%)$ & \multirow{2}{*}{0.069} \\
\hline Mix feed or other feed given & $4(26.7 \%)$ & $20(10.8 \%)$ & $24(12 \%)$ & \\
\hline \multicolumn{5}{|l|}{ Type of feed given at 1 month } \\
\hline Only Breast milk & $10(66.7 \%)$ & $169(91.4 \%)$ & $179(89.5 \%)$ & \multirow{2}{*}{0.003} \\
\hline Mix feed or other feed given & $5(33.3 \%)$ & $16(8.6 \%)$ & $21(10.5 \%)$ & \\
\hline \multicolumn{5}{|l|}{ Type of feed given at 3 month } \\
\hline Only Breast milk & $9(60 \%)$ & $158(85.4 \%)$ & $167(83.5 \%)$ & \multirow{2}{*}{0.011} \\
\hline Mix feed or other feed given & $6(40 \%)$ & $27(14.6 \%)$ & $33(16.5 \%)$ & \\
\hline \multicolumn{5}{|l|}{ Type of feed given at 6 month } \\
\hline Only Breast milk & $8(53.3 \%)$ & $130(70.3 \%)$ & $138(69 \%)$ & \multirow{2}{*}{0.173} \\
\hline Mix feed or other feed given & $7(46.7 \%)$ & $55(29.7 \%)$ & $62(31 \%)$ & \\
\hline
\end{tabular}

\section{Discussion}

This study addressed the role of antenatal counselling with different practices involved in Breastfeeding as well as duration of exclusive breastfeeding. During their pregnancy period $79.5 \%$ study subjects were provided counseling on exclusive breastfeeding. NFHS-4 data for Haryana showed that $82.8 \%$ women, with live birth in preceding 5 years before survey, received advice on breastfeeding in last 3 months of pregnancy. ${ }^{6}$ Goswami $S$ et al (2018) found that health functionaries were the source of counseling in $49.6 \%$ mothers in urban area as compared to only $29.2 \%$ in rural areas of Haryana. ${ }^{8}$ Tekaly $\mathrm{G}$ et al conducted study at Ethiopia in year 2018 found that $97.9 \%$ mothers received breastfeeding counseling at ANC clinic. ${ }^{9}$ Antenatal breastfeeding counselling received by $64.1 \%$ of the mothers in a study conducted at Karnataka, India. ${ }^{10}$ Women receiving antenatal counselling were $21 \%, 34.1 \%$ and $60 \%$ in studies by Bagul et al, Krishnan et al and Dhandapany et al respectively. ${ }^{11-13}$ This variability implies the difference in access to health information in different areas.

In the present study, $71.5 \%$ of mothers initiated breastfeeding within one hour of delivery and out of which $82.5 \%$ had received antenatal breastfeeding counselling but the association was statistically non-significant. This finding was similar to study done by Chethan $\mathrm{K}$ et al where $62.3 \%$ mothers initiated breastfeeding within one hour of delivery and it was statistically non-significant with mother's education and antenatal breastfeeding counselling. ${ }^{10}$ Choudhary R study found that there was significantly early initiation of Breastfeeding in intervention group (those who received Breastfeeding counselling admitted for delivery) than control group $(p=0.0001) .{ }^{14}$ Similar results on timing of initiation of Breastfeeding were seen by others. ${ }^{15,16}$ Studies reported that early initiation of Breastfeeding had powerful influence over the duration of EBF up to 6 months. ${ }^{17,18}$

The exclusive Breastfeeding practice at different time period (1 week, 1 month, 3 months and 6 months) had significant association with breastfeeding counselling in this study. A randomized controlled trial done in Northern India revealed that at 6 weeks Breastfeeding rates were significantly high in intervention group (those who received Breastfeeding counselling) than control group..$^{14} \mathrm{Th}$ is higher breast-feeding rates in intervention group is due to maternal motivation through counselling. Regular counselling at different time intervals resulted in sustained Breastfeeding in later life. ${ }^{19,20}$

Our study revealed that $7 \%$ women discarded colostrum and its association with antenatal breastfeeding counselling and mother's education was statistically no-significant. In the study done at Karnataka, $6 \%$ of mothers discarded colostrum and it was statistically non-significant with mother's education and antenatal breastfeeding counselling. ${ }^{10}$

In the present study, $90.8 \%$ of women practiced burping after feeding which is statistically non-significant with antenatal breastfeeding counselling and statistically significant with 
mother's education. The finding was different in study by Chethan $\mathrm{K}$ et al. ${ }^{10}$ where $79.5 \%$ practiced burping and it was statistically significant with breastfeeding counselling $(p=0.04)$ and mother's education $(p<0.001)$. The difference may be due to different in study area i.e urban area.

A large proportion of mothers were homemaker (94\%) and association of mother's occupation with Breastfeeding counselling was non-significant $(p=0.73)$ in this study. $A$ study of selected Mexican hospitals showed that counselling combined with babies staying with their mothers, significantly increased full breastfeeding among primiparous mothers. ${ }^{21}$

The prevalence of breastfeeding counselling was more among educated mothers and literacy had significant association with antenatal breastfeeding counselling $(p=0.03)$. The feeding practices like giving colostrum, starting feeding within 1 hour of delivery, burping after feed, exclusive breastfeeding for 1 week, 1 month, 3 months and 6 months etc was followed more among educated mothers compared to illiterate mothers. Previous studies also concluded that a higher maternal educational level was observed to favor EBF significantly $(p<0.05)$ when compared to illiterate mothers. ${ }^{22-24}$ The higher literacy rate of mothers may be attributed to their better understanding of advantages of early initiation of Breastfeeding and EBF for healthy survival and growth and development of their infant.

\section{Conclusion}

This study concludes that antenatal breastfeeding counseling is very useful for exclusive Breastfeeding and for improving infant breastfeeding practices. The number of antenatal visits and literacy of mother plays an important role in grabbing the opportunity of breastfeeding counselling. Thus, appropriate training programs for lactating mother is essential to ensure successful Breastfeeding.

\section{Limitation}

The limitation of the study was that it was a cross-sectional study and the study subjects were 6-12 months infants. The history about antenatal breastfeeding counselling and feeding practices was asked. The practices were not observed by the investigator himself leading to recall bias. Further cohort study may be planned on antenatal women who may be followed till 6 months after delivery and various breastfeeding practices may be observed to reveal the real scenario.

\section{Conflict of Interest: None}

\section{References}

1. Sunderlal, Adarsh, Pankaj. Textbook of Community Medicine. $4^{\text {th }}$ ed. New Delhi: CBS Publishers; 2018: 201-202.
2. Parthasarathy A, Menon PSN, Nair MKC et al. IAP Textbook of Pediatrics. $6^{\text {th }}$ ed. New Delhi: Jaypee Brothers Medical Publishers 2016: 143-152.

3. Azuine RE, Murray J, Alsafi $\mathrm{N}$ et al. Exclusive breastfeeding and under-five mortality, 2006-2014: a cross-national analysis of 57 low- and-middle income countries. Int J MCH AIDS 2015; 4(1): 13-21.

4. Infant and young child feeding. Model chapter for textbooks for medical students and allied health professionals. Geneva: World Health Organization; 2009: 1-3.

5. Guidelines for enhancing optimal infant and young child feeding practices. Ministry of health and family welfare. New Delhi: Government of India. 2013: 7-8.

6. International Institute for Population Sciences. National Family Health Survey, India. 2015-16: Haryana. Mumbai: IIPS; 2017.

7. Pandey VK, Aggarwal P, Kakkar R. Modified BG Prasad Socio-economic Classification, Update - 2019. Indian J Community Health 2019; 31(1): 123-125.

8. Goswami S, Khanna P, Verma R et al. Breastfeeding counselling and support: is it adequate? A descriptive study from Rohtak, India. Int J Res Med Sci 2018; 5(6): 2086-2091.

9. Tekaly G, Kassa M, Belete T et al. Pre-lacteal feeding practice and associated factors among mothers having children less than two years of age in Aksum town, Tigray, Ethiopia, 2017: a cross-sectional study. BMC Pediatr [Internet]. 2018 [cited 2019 mar 12]; 310. Available from: https://pubmed.ncbi.nlm.nih. gov/30253771/

10. Chethana K, Nelliyanil M, Anil M et al. Role of mother's education and antenatal counselling on Breastfeeding practices among women in coastal Karnataka: a community based cross sectional study. Int J Community Med Public Health 2020; 7: 122-127.

11. Bagul AS, Supare M. The infant feeding practices in an urban slum of Nagpur. J Clin Diagno Res 2012; 6(9): 1525-1527.

12. Krishnan L, Kaliaperumal S, Kommu PPK et al. Real and perceived problems in timely initiation of breastfeeding in a baby friendly hospital. Indian J Matern Child Health 2012; 15(2): 1-9.

13. Dhandapany G, Bethou A, Arunagirinathan A et al. Antenatal counselling on breastfeeding - is it adequate? A descriptive study from Pondicherry, India. Int Breastfeed J 2008; 3: 5.

14. Choudhary R, Meena C, Gothwal S et al. Effect of lactation counselling on Breastfeeding: randomized control trial. Int J Contemp Pediatr 2017; 4(5): 1-4.

15. Edmond KM, Zandoh C, Quigley MA et al. Delayed breastfeeding initiation increases risk of neonatal mortality. Pediatrics 2006; 117(3): 380-386. 
16. Gupta A, Dadhich JP, Faridi MM. Breastfeeding and complementary feeding as a public health intervention for child survival in India. Indian J Pediatr 2010; 77(4): 413-418.

17. Vaidya K, Sharma A, Dhungel S. Effect of early motherbaby close contact over the duration of exclusive breastfeeding. Nepal Med Coll J 2005; 7(2): 138-140.

18. Haider R, Ashworth A, Kabir I et al. Effect of communitybased peer counsellors on exclusive breastfeeding practices in Dhaka, Bangladesh: A randomised controlled trial. Lancet 2000; 356(9242): 1643-1647.

19. Salariya EM, Easton PM, Cater JI. Duration of breastfeeding after early initiation and frequent feeding. Lancet 1978; 2(8100): 1141-1143.

20. Nankunda J, Tumwine JK, Soltvedt A et al. Community based peer counsellors for support of exclusive breastfeeding: Experiences from rural Uganda. Int Breastfeed J 2006; 1: 19.

21. Perez-Escamilla R, Segura-Millán S, Pollitt E et al. Effect of the maternity ward system on the lactation success of low-income urban Mexican women. Early Hum Dev 1992; 31(1): 25-40.

22. Ogbonna C, Okolo SN, Ezeogu A. Factors influencing exclusive breast-feeding in Jos, Plateau State, Nigeria. West Afr J Med 2000; 19(2): 107-110.

23. Ekanem A, Ekanem AP, Asuquo A et al. Attitude of working mothers to exclusive breastfeeding in Calabar municipality, Cross River State, Nigeria. J Food Res 2012; 1(2): 71-75.

24. Kumar V, Kumar L, Diwedi P. Morbidity related to feeding pattern in privileged urban and under privileged rural infants. Indian Pediatr 1981; 18(10): 743-749. 